\title{
OS PROGRAMAS SOCIAIS E A INSERÇÃO INTERNACIONAL DO BRASIL: UM ESTUDO DO GOVERNO LULA DA SILVA
}

SOCIAL PROGRAMS AND INTERNATIONAL INSERTION OF BRAZIL: A STUDY OF LULA DA SILVA

\begin{abstract}
Augusto Leal Rinaldi*
RESUMO: O artigo pretende analisar em que medida as políticas sociais adotadas pelo governo Lula da Silva durante seus dois mandatos, principalmente o programa Bolsa Família, impactaram na projeção internacional do Brasil, considerando que o discurso do presidente de combate à pobreza e sua busca por maior justiça e igualdade social no cenário doméstico implicou numa tentativa de impulsionar a inserção internacional do país. Nossa hipótese é a de que o sucesso em diversas iniciativas empregadas por Lula da Silva dentro do quadro de exclusão social, pobreza e distribuição desigual de renda que pinta o cenário interno brasileiro deu maior destaque para o país no cenário externo. Isso acontece devido à relevância que o tema social adquire nos Fóruns Multilaterais de discussão e na busca do Brasil por atuar cada vez mais assertivamente nos diversos meios diplomáticos para defender sua iniciativa. Esta proposição está associada à nova configuração que as políticas sociais brasileira ganharam durante o governo, canalizadas, agora, na ideia de maior alcance de seus programas e resultados e na tentativa de impulsionar a projeção dos interesses nacionais no sistema internacional, sempre acompanhados da perspectiva de mudança social.
\end{abstract}

Palavras-Chave: Políticas sociais. Política externa brasileira. Inserção internacional.

\footnotetext{
* Mestrando em Ciência Política pelo Programa de Pós-Graduação em Ciência Política da Universidade Estadual de Campinas (UNICAMP). Esta pesquisa foi financiada pela FAPESP.
} 
ABSTRACT: The article analyzes the extent to which social policies adopted by Lula da Silva during his two terms, especially the Bolsa Familia program, impacted the international projection of Brazil, considering that the president's speech to combat poverty and its search for greater justice and social equality on the domestic scene involved an attempt to boost the country's international insertion. Our hypothesis is that the success of various initiatives employed by Lula da Silva in the framework of social exclusion, poverty and unequal income distribution that paints the Brazilian domestic scenario gave greater prominence to the country in the international scenario. This happens because of the relevance that the social issue gets in the multilateral forums of discussion and in search of Brazil to act more assertively in various diplomatic means to defend their initiative. This proposition is associated with the new configuration that social policies have gained during the Brazilian government, channeled, now, the idea of greater scope and results of their programs and attempt to boost the projection of national interests in the international system, accompanied by the prospect of social change.

Key-words: Social politics; Brazilian foreign policy; international insertion.

\section{INTRODUÇÃO}

Após o término dos dois mandatos de Luiz Inácio Lula da Silva (2002-2006; 2007-2010) na presidência da República, faz-se necessário realizarmos um resgate analítico de todo o período no qual o ex-presidente esteve à cargo da nação. Para isso, o faremos sob determinado recorte objetivo: analisaremos o impacto dos programas sociais implantados ao longo dos oito anos sobre o projeto de inserção internacional do país. Dessa forma, este artigo se enquadra num marco específico de análise, uma vez que pretende estudar apenas duas vertentes do total de políticas públicas que compõe a agenda governamental - políticas sociais e política externa -, não procurando se estender nas diversas outras áreas geridas pelo Estado. 
Primeiramente, é sabido que o Brasil possui um histórico projeto de inserção internacional que parte, principalmente, de seu relacionamento regional sul-americano (Almeida, 2004). A ênfase dada por Lula da Silva ao contexto regional é integrante de uma parte de recomendações do Itamaraty, que enxerga na América do Sul e nos parceiros do Mercado Comum do Sul (MERCOSUL), em particular, grandes oportunidades de investimentos, trocas comerciais, parcerias políticas, mobilização cultural e integração regional. No entanto, diferentemente de momentos históricos anteriores, durante os últimos oito anos de governo o Brasil se aproximou mais da região e demonstrou claramente sua opção sul-americana de parcerias, com o propósito de engrenar maior desenvolvimento sócio-econômico do país e da própria região, fazendo da diplomacia a principal ferramenta para alcançar tais interesses.

Alguns dos elementos que caracterizam a região sul-americana - todo o continente latino-americano, poderíamos dizer - são a alta concentração de riquezas, as altas taxas de pobreza e marginalização social e a instabilidade política. Esses fatores são comuns a praticamente todos os países, em maior ou menor grau relativo. Nesse sentido, as iniciativas do governo Lula da Silva de enfrentamento do quadro de exclusão social, pobreza e injustiça no cenário doméstico brasileiro a partir de políticas sociais redistributivas são vistas como proposições que procuram transformar o cenário nacional num ambiente mais democrático, mais respeitador, menos selvagem. Esta iniciativa, por conseguinte, é interpretada por outros países - os latino-americanos em geral - como algo inovador, vanguarda. São assim caracterizadas principalmente devido à maneira pela qual foram concebidas e adotadas no Brasil e em outros países da América Latina, como no México ${ }^{1}$, por exemplo (Mattei, 2008).

Nesse sentido, seria pertinente analisarmos a relação estabelecida entre política social e engajamento externo, que procuraríamos realizar com a finalidade de compreender de que forma esta prática política impactou nos objetivos de projeção internacional do Brasil. A questão da projeção externa brasileira, para fins deste 
artigo, será tratada no sentido de maior participação brasileira nos fóruns multilaterais de discussão, principalmente nos fóruns de diálogo Sul-Sul.

Procuraremos demonstrar que os impactos da aplicação destes programas sociais foram positivos para a imagem externa do país e para sua projeção internacional. Não somente a figura carismática do presidente Lula da Silva contribuiu para essa maior visibilidade do país, como também a eficácia destes programas e os resultados obtidos $^{2}$ legitimaram e criaram as condições necessárias, porém não suficientes, para uma atuação mais "ativa e altiva" de nossa política externa, como denominou o ex-chanceler Celso Amorim. Contribuindo para isso, o próprio peso econômico do Brasil poderia dar envergadura a um programa continental de políticas socialmente redistributivas (Sader, 2007).

Dentro do quadro nacional, de forma a projetar sua influência política na região latino-americana e se inserir nos variados temas da agenda internacional, o presidente Lula da Silva ampliou de forma significativa os programas de transferência de renda condicionada no Brasil e impulsionou sua "internacionalização", demonstrando a aplicabilidade do programa, seu gerenciamento e seus mecanismos de avaliação a outros países da região. Na medida do possível, o governo brasileiro praticou uma diplomacia solidária no campo da cooperação internacional.

Nosso trabalho está metodologicamente estruturado da seguinte maneira: em primeiro lugar, apresentaremos os contextos nacional e internacional em que o governo Lula da Silva esteve imerso, com a finalidade de demonstrar quais as principais características e fatores que permitiram a ele desenvolver os programas sociais e buscar uma atuação externa mais engajada. Na seção seguinte, faremos uma exposição histórica da implantação das políticas sociais no Brasil, apontando seus principais desdobramentos domésticos durante o período em que estamos considerando. Em seguida, analisaremos as principais iniciativas do governo no campo da diplomacia, procu-

\footnotetext{
${ }^{2}$ Segundo Dulci (2009), cerca de $25 \%$ da redução da pobreza extrema no Brasil se devem ao programa Bolsa Família.
} 
rando dar ênfase às práticas multilaterais de negociação político-econômica. Na penúltima seção, os Organismos Internacionais serão nosso foco, apresentando análises elaboradas por organizações tais como Fundo Monetário Internacional e CEPAL. Por fim, concluiremos no sentido de amarrar toda a linha argumentativa do trabalho, apontando para o fato de que a ligação entre política externa e política social pode ser estabelecida, e sua aplicabilidade no campo de políticas públicas foi uma escolha do governo entre tantos outras alternativas possíveis.

\section{O CONTEXTO DO GOVERNO LULA DA SILVA}

A eleição de Luiz Inácio Lula da Silva para presidente da República no início do século XXI foi um fato marcante na história política brasileira. A conjuntura internacional no início do período Lula era favorável à expansão dos negócios brasileiros. Com o comércio internacional cada vez mais intenso e a ascensão da China e Índia como grandes países consumidores de matérias-primas, o momento era propício ao Brasil a tomar algumas medidas macroeconômicas e seguir o mesmo caminho de seus parceiros emergentes. A questão da inserção internacional do país, nesse quadro favorável, é assim descrito pelo diplomata Samuel Pinheiro Guimarães (2001):

Nesse quadro de crescente instabilidade, disparidade, violência e multipolaridade, cujas tendências estruturais são em grande medida adversas ao Brasil, no qual as múltiplas e complexas relações entre os atores, principalmente, mas não apenas Estados, são relações por vezes de cooperação, mas principalmente de competição e de conflito, é que se tem de definir uma estratégia realista de inserção internacional do Brasil. Essa estratégia tem de ser construída e executada a partir dos três desafios da sociedade brasileira, que são a redução das extremas disparidades sociais; a eliminação das crônicas vulnerabilidades externas e a realização acelerada do seu potencial. (Guimarães, 2001, p. 9). 
É a partir dessa interpretação do cenário externo que devemos analisar as estratégias de inserção internacional adotadas pelo governo Lula. $\mathrm{O}$ reconhecimento e entendimento dos desafios brasileiros apontados acima por Guimarães são de fundamental importância para analisarmos as políticas praticadas internamente para 0 determinado fim de projeção externa. Focaremos, contudo, no vértice da redução das disparidades sociais internas, que foi o principal pilar de sustentação do governo. A temática das políticas sociais adquiriu grande destaque internacional, tendo sido abordada principalmente por Organizações Internacionais de grande porte, tais como o Fundo Monetário Internacional (FMI), Banco Mundial e outros braços socioeconômicos da Organização das Nações Unidas (ONU). Mas também países emergentes em seus encontros bilaterais e multilaterais abordavam essa temática, como nas reuniões do BRICS, IBAS, MERCOSUL, G-20 entre outros.

Nessa conjuntura, o tema social encontrou grande respaldo em alguns países de menor poder relativo, inclusive no Brasil, que procurou designar o status de prioridade às políticas sociais na conformação de suas políticas domésticas e construir e articular programas interessantes na área do enfrentamento da pobreza e miséria que assolam insistentemente a sociedade brasileira. Na interpretação do Itamaraty:

Os programas sociais implementados pelo Governo, entre 2003 e 2010 priorizam o combate à fome e à pobreza, a universalização e a qualificação da educação, a geração de emprego e renda para os mais pobres, a ampliação dos serviços de saúde, o combate às desigualdade socioeconômicas e promoção da igualdade de raça e gênero. (MRE, 2010).

Foi nessa linha de argumentação que o governo procurou gastar maior energia no desenvolvimento de suas políticas socioeconômicas. O impacto que a adoção dessas políticas tem sobre a inserção externa do país reside no fato de que o país levou à cabo programas sociais de grande alcance ${ }^{3}$ cujo êxito e repercussão internacional

\footnotetext{
${ }^{3} \mathrm{O}$ maior programa social adotado pelo Governo Federal foi o Bolsa Família, que uniu quatro programas de renda mínima: Bolsa-Escola, Bolsa-Alimentação, Vale Gás e Cartão-Alimentação (Araújo, 2006). 
possibilitaram a elaboração de propostas de cooperação com outros países em desenvolvimento, e também à divulgação das políticas sociais no país. Ainda de acordo com o Itamaraty:

O bom gerenciamento das políticas sociais e os consequentes resultados na redução da pobreza e da exclusão têm permitido à política externa brasileira produzir discurso capaz de transformar, mundialmente, a imagem que o Brasil tem no que tange à desigualdade social e à concentração de renda. (MRE, 2010).

Assim, fora essencialmente dessa forma que o governo Lula da Silva procurou levar adiante a estratégia de inserção internacional do Brasil, colocando como carro-chefe dessa estratégia as políticas sociais de seu governo - principalmente o programa Bolsa Família e seus positivos resultados - e procurando, na medida do possível, diversificar suas parcerias estratégicas com a finalidade de articular melhor sua projeção externa. A diversificação de parcerias, a construção de parcerias de geometria variável (Pecequilo, 2008) foram estratégias importantes nesse sentido, que conformaram a nova abordagem que o país adotou a partir do início do século XXI. Concluiremos, por conseguinte, que as iniciativas do governo Lula da Silva no sentido de democratizar as relações assimétricas de poder internacional a partir dessas iniciativas de cooperação internacional, aliada a adoção de políticas sociais no cenário doméstico foram as principais linhas-mestras de atuação do governo. É a partir dessa interpretação que iremos trabalhar adiante, aliando políticas sociais com inserção internacional.

\section{AS POLÍTICAS SOCIAIS NO BRASIL}

Historicamente, não se pode falar da política social de Lula da Silva sem antes recorrer ao seu antecessor na Presidência da República, Fernando Henrique Cardoso (1994/2002). Sua atuação no campo social fora o ponto de partida para o direcionamento das políticas sociais no governo seguinte. 
Ancorado no sucesso do Plano Real, de 1994, Fernando Henrique Cardoso fora eleito presidente neste mesmo ano. Entre outros tantos alcances dessa política macroeconômica de estabilização monetária, no setor social, inicialmente, ela fora bastante perceptível. José Prata Araújo (2009) argumenta que os mais pobres foram favorecidos com o aumento do poder de compra - visto a valorização cambial - e com a redução importante da pobreza logo no início do plano. Segundo o documento "Estratégia de superação da pobreza e da equidade de gênero", da CEPAL, em 2004:

Após anos de instabilidade política e econômica no país, temse no primeiro mandato do presidente Fernando Henrique Cardoso (1995-1998) a ordenação de um programa de desenvolvimento social calcado em diretrizes de estabilidade macroeconômica, desenvolvimento sustentável, austeridade fiscal e reforma do Estado, articuladas com princípios de universalidade, participação e descentralização. (CEPAL, 2004, p. 1).

Entretanto, numa análise de longo prazo, as políticas neoliberais no Brasil foram tomando formas talvez "não previstas", como maior concentração da renda, riqueza e propriedade, aumento das disparidades socioeconômicas, entre outras.

As críticas que foram feitas ao governo Cardoso com relação às suas políticas sociais residiam no fato de que apesar de serem concretamente propostas de reforma dos programas sociais e do sistema de proteção social, o acesso a esses benefícios era muito limitado e os custos para a manutenção desses programas eram transferidos diretamente aos contribuintes.

De qualquer forma a atuação de Cardoso no sentido de "abrir o caminho" para as politicas sociais no Brasil, embora influenciado pela Constituição "Cidadã" de 1988, foi um fator importante para o governo Lula da Silva prosseguir nesse caminho e ampliá-lo como defendia em seus discursos.

Diante de um contexto de insatisfação popular com o nível de bem estar econômico e social evidenciado a partir do início dos anos 
2000, a decisão governamental sob a liderança do recém-empossado presidente Lula foi a de adotar uma linha mais pró "social" nas políticas públicas, atribuindo grande ênfase às políticas direcionadas à parcela mais pobre da sociedade.

A criação e o lançamento do programa Bolsa Família aconteceu em meados de 2003, com o presidente apontando as principais diretrizes do programa e dotando-lhe de uma áurea simbólica única a seus futuros efeitos sobre o conjunto da sociedade. Instituído pela Medida Provisória n ${ }^{\circ} 132$, de 20 de outubro de 2003, o programa Bolsa Família unificou programas antigos de transferência de renda que remontam ao período Cardoso, no qual foram criados e agora unificados os programas Bolsa Escola, Auxílio Gás, Bolsa Alimentação e Cartão Alimentação ${ }^{4}$. A unificação de tais programas possibilitou ao Governo Federal a ampliação do alcance dessas políticas e ao reordenamento dos investimentos nessas áreas.

O programa Bolsa Família tem como principais objetivos a redução das disparidades econômico-sociais, dar suporte às famílias mais pobres do país e garantir o direito à escolarização e à saúde a todos os cidadãos. É relevante notarmos que o escopo principal do programa é a promoção dos indivíduos, principalmente os situados na base da pirâmide social. Esse objetivo é de especial atenção na medida em que procura não só atribuir ênfase no enfrentamento da pobreza e da miséria, mas também por suscitar uma possível "promoção" social dos indivíduos, contribuindo para a realização de seu potencial socioeconômico.

O ponto crucial o qual os principais estudiosos e observadores de políticas públicas apontam para caracterizar a fraqueza do programa é a falta de sua institucionalização como programa de Estado. Atualmente, o Bolsa Família é um programa de governo, podendo suas atribuições serem ampliadas ou reduzidas em governos futuros, dependendo da conjuntura na qual ele se encontre. Embasaremos com maior propriedade nossa argumentação com as palavras de um estudioso da área:

\footnotetext{
${ }^{4}$ Disponível em: http://www.mds.gov.br/bolsafamilia 
Tais condições políticas permitem levar adiante a política de redução da pobreza, com base num consenso interno suficiente. Sobre esse fundamento, um passo estratégico é a institucionalização dos programas: eles devem se situar como políticas de Estado, não só de um governo ou de um governante, como ocorre em alguns casos na América Latina. E a razão é óbvia: a associação dos programas com determinados governos, governantes ou partidos políticos põe em risco a sua continuidade quando mudam os governos e os partidos no poder. Isso só se pode resolver pela institucionalização, adotando-se uma legislação clara de definição de direitos e deveres dos cidadãos e do Estado no tocante à garantia de renda básica. (Dulci, 2009, p. 12).

Como o autor acima ressaltou, corre-se o risco de a continuidade do programa ser rompida quando os governos e os partidos no poder mudarem, prejudicando a garantia desses benefícios aos que mais necessitam dela, podendo essa situação, num cenário extremado, acentuar cada vez mais a pobreza e a miséria no país. Para se enfrentar de maneira eficaz e eficiente esse quadro brasileiro de injustiça social é preciso dar não só continuidade ao programa ao longo do tempo, mas ampliá-lo cada vez mais, procurando atingir o maior número de pessoas possível e qualificando-as com o melhor ensino disponível e dotando-as de recursos cada vez mais amplos para a realização de seu potencial. Evidente que essas tarefas, além de serem complexas e dispendiosas, caso venham a ser rompidas por governos posteriores, podem prejudicar os resultados já alcançados.

Atualmente, faz-se necessário a ampliação do alcance das políticas do Bolsa Família. Ainda que abarque cerca de 11 milhões de famílias por todo o Brasil, respondendo essa cifra por uma média de 40 milhões de pessoas (Marques; Mendes, 2007), o programa precisa ser periodicamente revisado e atualizado, principalmente para poder de tempos em tempos retirar mais pessoas da situação de pobreza e possibilitar sua emancipação, contribuindo para o reequilíbrio da justiça social.

No tocante aos resultados obtidos através da implantação desses programas sociais, ainda que não possam ser verificados em todas suas áreas de concentração - visto que não seria cabível num 
trabalho desta natureza -, podemos apontar algumas áreas do campo doméstico em que houve melhora nos índices de redução da disparidade socioeconômica e no desenvolvimento de capital humano. Cabe destacar que a participação das políticas sociais que envolvem transferência direta de renda às famílias cresceu de $6,9 \%$ do PIB em 2002 para $8,6 \%$ em 2008, e o salário mínimo real cresceu 39\% no mesmo período (Barbosa; Souza, 2010). Com relação aos resultados do referido programa social, afirma Pochmann (2010):

Sem as transferências monetárias, o Brasil teria, em 2008, 40,5 milhões de pessoas com rendimento de até $25 \%$ do salário mínimo nacional. Com a complementação de renda pelas transferências, o Brasil registra 18,7 milhões de pessoas com até um quarto de salário mínimo mensal. Em resumo, são 21,8 milhões de pessoas que conseguem ultrapassar a linha de pobreza extrema (até $25 \%$ do salário mínimo per capita). Em 1978, o efeito da política de transferência monetária impactava somente 4,9 milhões de pessoas. (Pochmann, 2010, p. 6).

O programa Bolsa Família contribuiu decisivamente para a redução da pobreza e da desigualdade social no país. Dados do Ministério do Desenvolvimento Social apontam houve aumento médio de 48,7\% na renda familiar per capita da população atendida. Em regiões como no Norte e Nordeste, o aumento de renda chega a 60\% (MDS, 2010). Somente o Governo Federal aplicou em seguridade social, em 2008, a soma de R $\$ 372$ bilhões, aproximadamente 13\% do PIB brasileiro.

Pesquisas realizadas no âmbito do MDS revelaram que 93\% das crianças e $82 \%$ dos adultos das famílias beneficiárias fazem três ou mais refeições diárias. A Pesquisa Nacional de Demografia e Saúde, realizada em conjunto pelo Ministério da Saúde e pelo Centro Brasileiro de Análise e Planejamento (CEBRAP), indicou que a desnutrição infantil crônica no Nordeste teve uma significativa queda de $73 \%$ entre 1996 e 2006. A chamada nutricional que fora promovida em conjunto com o Ministério da Saúde na região do Semiárido em 2005, para avaliar redução da desnutrição infantil, demonstrou que o Bolsa Família teve impacto de 29\% na redução da desnutrição (Ananias, 2009). 
Dados do IPEA (2010) demonstram que cerca de 22 milhões de trabalhadores ativos, com ou sem carteira, e mais outros 18 milhões de beneficiários da Previdência e Assistência Social receberam uma importante injeção de recursos que foi direcionada integralmente ao consumo. Esta medida contribuiu, em certa medida, para o aquecimento da economia e para o estímulo da produção. Adicionalmente, esse aquecimento possibilitou também a recuperação dos níveis de confiança na economia, o que é muito importante para a avaliação dos riscos econômicos no Brasil e, principalmente, para atribuir maior credibilidade ao país para se inserir no sistema internacional.

Não somente na questão da redução das desigualdades podemos verificar os impactos positivos dos programas, mas também em outra importante área social, como a educação. Segundo o Banco Mundial $^{5}$, em 2004, 97,1\% dos jovens entre 7 e 14 anos estavam matriculados no ensino fundamental. Esses dados nos concedem informações importantes para compreender de que forma essas políticas impactaram na sociedade brasileira e de que forma elas construíram uma sociedade mais justa e mais capacitada, do ponto de vista econômico-social (Weissheimer, 2006).

De todo modo, como a delimitação da natureza deste trabalho não nos permite estender a uma análise mais profunda dos impactos nacionais em todas as áreas de atuação desses programas, nos limitaremos a apenas apresentar essa argumentação, que ainda que não seja de todo modo exaustiva, é explicativa por si mesma. Não podemos deixar de destacar, também, o importante papel do Sistema Único de Saúde (SUS) como instrumento de proteção social da população, que trabalha juntamente com o programa Bolsa Família e com diversos outros programas governamentais relacionados à saúde e ao bem estar dos indivíduos.

Os positivos resultados alcançados pelas políticas sociais adotadas pelo governo Lula da Silva, embora sejam discutíveis em diversos aspectos, nos permitem apontar uma redução significativa

\footnotetext{
${ }^{5}$ Disponível em: http://www.bancomundial.org.br/index.php/content/
} 
no quadro de miseráveis e pobres no Brasil e uma melhora na questão de desigualdade social.

O programa Bolsa Família, assim como qualquer outro programa social, não é estático nem isento de imperfeições. Há falhas estruturais e operacionais que precisam ser revistas e reordenadas e seu processamento deve ser contínuo. Porém, no que se refere ao seu principal escopo ele ainda é parcialmente eficaz. Não nos alongaremos mais nessa discussão, embora ela seja necessária em outra ocasião. Tentaremos, na seção seguinte, demonstrar o impacto da adoção dessas políticas sociais e seus positivos resultados sobre a inserção externa do Brasil, procurando apontar em que medida elas contribuíram para nossa projeção internacional.

\section{A POLÍTICA EXTERNA}

A política exterior brasileira durante o governo Lula da Silva fora marcada, principalmente, pela universalização das relações econômico-políticas.

De modo a compactar as principais diretrizes que nortearam a atuação externa do Brasil no período, nos utilizaremos das importantes análises realizadas por Vigevani e Cepaluni (2007), as quais contribuem para o entendimento de toda a complexa dinâmica que envolve a projeção externa e a construção de alianças internacionais para a defesa de nossa soberania. Podemos apontar, então, as principais mudanças percebidas na política externa do governo Lula e suas diretrizes indiretas como:

$\left(1^{a}\right)$ contribuir para a busca de maior equilíbrio internacional, procurando atenuar o unilateralismo; $\left(2^{\mathrm{a}}\right)$ fortalecer relações bilaterais e multilaterais de forma a aumentar o peso do país nas negociações políticas e econômicas internacionais; $\left(3^{\mathrm{a}}\right)$ adensar relações diplomáticas no sentido de aproveitar as possibilidades de maior intercâmbio econômico, financeiro, tecnológico, cultural etc.; e ( $\left.4^{\mathrm{a}}\right)$ evitar acordos que possam comprometer a longo prazo o desenvolvimento. (VIGEVANI; CEPALUNI, 2007, p. 20). 
É a partir deste esquema que iremos desenvolver nossa argumentação, tentando apontar alguns dos êxitos da política exterior brasileira do período recente bem como apontar alguns dos possíveis cenários onde os obstáculos criados pela resistência externa dos países inviabilizaram nossa atuação.

\subsection{A busca pelo equilíbrio internacional}

O governo Lula e sua equipe focaram a agenda de política externa no sentido da combinação de eixos verticais e horizontais de parcerias. "A política externa do século XXI transforma e atualiza o passado ao mesclar equilibradamente Norte-Sul e Sul-Sul." (Pecequilo, 2008, p.1). A resposta aos desafios globais que emergem no sistema internacional não podem ser mais concebida de forma unilateral. Menos ainda, a perseguição dos interesses domésticos não se completa sem a cooperação e o diálogo entre os países, por isso a busca por maior equilíbrio internacional no sentido de reduzir as posições hegemônicas e "democratizar" o sistema não podem ser dirigidas de forma unilateral. É preciso posições harmônicas, congruentes. E isso só pode ser encontrado a partir de esforços em conjunto, de forma multilateral, participativa. O governo Lula da Silva apostou nesta perspectiva, e muito de seu pragmatismo está relacionado a esta concepção de política internacional.

A noção de multipolaridade e de equilíbrio internacional estão arraigados nos discursos do governo Lula, e suas iniciativas nesse campo são importantes eixos estratégicos de nossa política exterior, podendo ser verificados nas diversas alianças de geometria variável que construímos e na perspectiva de maior participação brasileira - e dos países do Sul, em geral - nos debates e decisões de grandes temas da agenda internacional.

\subsection{As relações multilaterais}

Houve iniciativas do governo Lula no campo da política externa no sentido da multipolaridade. A ênfase atribuída às coalizões 
Sul-Sul, principalmente, e para a integração regional a partir do Mercosul foram as linhas-mestres de atuação externa brasileira. Por coalizões Sul-Sul, entendemos as relações diretas entre países que se situam ao "sul" geográfico do globo, que são historicamente conhecidos como países da periferia do sistema internacional ou, como atualmente alguns deles são denominados, países emergentes. Nesse sentido, China, Índia, África do Sul, Coréia do Sul, Argentina e outros são os países centrais nessa conceituação, além do Brasil. É com base na noção de justiça social e, acima de tudo, na diversificação de parcerias compreendida na lógica de alianças de geometria variável de poder que a diplomacia de Lula investiu para assegurar a projeção externa de nossos interesses imediatos. Segundo André Luiz Reis da Silva (2010), com a mudança de governo, em 2003, a política multilateral ainda manteria centralidade na ação diplomática brasileira, porém seu conteúdo e suas principais estratégias de inserção externa sofreriam mudanças e reorientações.

Nas palavras de André Luiz Reis da Silva (2010):

Dessa forma, considera-se que a política externa brasileira na primeira década do novo milênio está se constituindo sobre uma nova matriz de inserção internacional, que busca aprofundar a integração regional na América do Sul, retomar a tradição multilateral do Brasil de perfil crítico às assimetrias internacionais, a busca de parcerias estratégicas com países similares em todos os continentes. Entretanto, ao contrário da matriz desenvolvimentista dos anos 1970-1980, a nova matriz da política externa é mais fluida e multidimensional, com arranjos políticos, alianças e parcerias estratégicas flexíveis, combinando atores, cenários e interesses. A multidimensionalidade deriva da atuação e articulação diplomáticas nos vários planos (bilateral, multilateral e regional). Assim, as parcerias estratégicas são flexíveis e combinadas tematicamente. (Silva, 2010, p 23).

Em vista aos países asiáticos, a relação com o Brasil passou a ser prioritária como instrumento de barganha em relação aos outros pólos de poder internacional. China e Brasil apresentaram posicio- 
namentos similares em questões variadas da agenda internacional, se opondo ao protecionismo adotado pelas grandes potências ao mesmo tempo em que estreitavam as responsabilidades comuns em matéria de desenvolvimento econômico e cooperação multilateral (Altemani de Oliveira, 2006). Ainda no recorte asiático, o principal interesse que moveu as relações entre esses países estava diretamente relacionado ao investimento econômico e à diversificação de parcerias econômicas. Segundo Altemani de Oliveira (2006):

O presente interesse mútuo, além da busca das complementaridades óbvias em termos de comércio e alianças políticas tanto nos planos bilaterais quanto nos multilaterais, demonstra a vontade política de estreitamento de relações em função da necessidade de estabelecimento de parcerias, de um lado, no processo de distribuição de poder internacional e, de outro, na disputa pela garantia de acesso a mercados. (Altemani De Oliveira, 2006, p. 181).

O que se buscou foi a conformação de uma frente única de atuação entre os países, como um bloco capaz de se orientar no mesmo sentido, ainda que em alguns momentos haja orientações distintas entre eles. Essa atuação é entendida como um processo que parte do estreitamento dos interesses comuns e da defesa de suas reinvindicações imediatas, principalmente as de caráter econômico e de desenvolvimento tecnológico.

Enfocando, agora, nas relações com os países da América do Sul e do Mercosul, as estratégias de Lula da Silva nesse sentido foram também importantes. Segundo Guimarães (2001), a América do Sul constitui a área imediata de interesses brasileiros e de inserção internacional do Brasil. O Mercosul é considerado a plataforma direta de projeção externa dos interesses brasileiros. Em termos de cooperação com os países do Cone Sul, cabe destacar a principal dimensão atribuída ao Mercosul, com maior aproximação da Argentina, o principal mercado brasileiro e parceiro político do Brasil na região. "A diplomacia brasileira incluiu em sua agenda um projeto mais claro de construção de uma liderança regional articulado à segurança regio- 
nal, à defesa da democracia, aos processos de integração regional e às perspectivas de desenvolvimento nacional" (Saraiva, 2007, p. 48).

O interesse imediato no Mercosul não é uma escolha aleatória. As oportunidades de crescimento e intensificação das relações comerciais, políticas e culturais entre os países do Cone Sul são perceptíveis. É preciso investir em maiores esforços no sentido de aprofundar a integração política-econômica da região e utilizar esse bloco regional como plataforma de projeção externa de poder dos países. A defesa desses países em forma de bloco regional frente aos desafios das grandes potências é outra forma de barganhar e ganhar autonomia internacional para defender seus interesses próprios. Esse aprofundamento do bloco deve passar, necessariamente, pela mediação direta do Brasil e da Argentina, que são os pivôs desse projeto e os países com maior capacidade de aplicar recursos para seu desenvolvimento. Assim, para Paulo Roberto de Almeida (2004):

Para Lula, o Mercosul constitui, manifestamente, a prioridade mais importante da diplomacia brasileira e um plano para o seu reforço e aprofundamento até 2006 foi apresentado aos demais parceiros: trata-se da implementação de normas já adotadas ou da finalização de um conjunto de outras ações e medidas já negociadas. (Almeida, 2004, p. 13).

No tocante ao relacionamento com os Estados Unidos, diferentemente do empenho dispendido pelo governo antecessor, a relação fora marcada por avanços e retrocessos em diversas áreas. $\mathrm{O}$ foco de nosso estudo se concentra nas parcerias horizontais Sul-Sul, portanto um estudo mais aprofundado das relações bilaterais Estados Unidos-Brasil, que são marcadamente assimétricas e reprodutoras da clivagem Norte-Sul, não têm espaços nesta discussão. Vale ressaltar, entretanto, que o histórico relacionamento entre os dois países nunca deixou de ser uma prioridade para o Brasil em matéria de aliança diplomática, mas a posição defendida por Lula da Silva diante dos desafios regionais fora de tímida contestação frente aos interesses americanos, principalmente no tocante à ALCA e aos contenciosos no setor do algodão e do milho (Oliveira, 2005; Vigevani; 
Cepaluni, 2007). Um caso exemplar da contestação brasileira frente aos interesses norte-americanos foi a questão do contencioso das patentes na Organização Mundial do Comércio (OMC), nos anos 2000.

Os resultados desse processo de construção de parcerias Sul-Sul foram os mais variados. Podemos apontar, por exemplo, a recente aproximação com Índia e África do Sul (IBAS). Outras parcerias foram criadas como o grupo econômico G-206 , na reunião ministerial de Cancún, em 2003, com a participação relevante do Brasil, principalmente a partir de 2008. Miriam Gomes Saraiva (2007), aponta que o G-20 tornou-se e ainda permanecerá sendo um dos fóruns multilaterais mais importantes para a atuação conjunta dos países do Sul, inclusive para o Brasil. A atuação da diplomacia brasileira no sentido de avançar sobre as negociações comerciais - relacionado principalmente ao tema agrícola - possibilitou ao Brasil ocupar um lugar de global player nestas negociações. Segundo o Ministério das Relações Exteriores (2010):

O G-20 busca o equilíbrio entre duas características fundamentais para os arranjos internacionais: legitimidade e eficácia. Ao congregar as economias sistemicamente importantes, o Grupo abre espaço para participação de países que, anteriormente, não tinham voz no cenário internacional, ao menos no que se refere aos temas econômico-financeiros. Ademais, mostrou-se capaz de tomar decisões rapidamente e em ambiente de grande pressão, provando-se exercício eficaz para lidar com situações de crise. (MRE, 2010).

Além disso, o país é integrante do grupo dos BRIC e do G-47. O grupo dos BRIC fora uma importante aliança construída pelos países integrantes com a finalidade de se articularem como um bloco, buscando defender seus interesses com autonomia e alto poder de barganha. Nas palavras de Altemani de Oliveira (2006):

\footnotetext{
6 "Grupo de países interessados no fim dos subsídios e das subvenções às exportações de produtos agrícolas e em um maior acesso aos mercados tradicionais protecionistas do Norte." (Almeida, 2004, p. 6). O Brasil se enquadra nestes países.

${ }^{7}$ Grupo de países que se apoiam mutuamente a fim de obter maior respaldo para a intenção de conseguir um assento permanente no Conselho de Segurança da ONU. Entre eles estão Brasil, Japão, Índia e Alemanha. 
Mais do que resultados práticos, a criação do G-20 deve ser vista sob a ótica da retomada da capacidade de articulação política do Brasil, mesmo que esboçada em foro tão inusitado. Também a criação do G3, grupo de coordenação política criada pelo Brasil, África do Sul e Índia. São todos movimentos que refletem a vontade de esboçar um novo modelo de cooperação Sul-Sul, que não deve, entretanto, erigir-se como alternativo às relações com o Norte. (Altemani De Oliveira, 2006, p. 191).

Além desses exemplos de coordenação diplomática, é válido mencionar também a assunção pelo país, desde 2004, do comando das operações de paz no Haiti, indicado pelas Nações Unidas para a reestruturação física e política do país. O papel de liderança do Brasil nesta Missão das Nações Unidas para a Estabilização do Haiti (Minustah) demonstra a preocupação da América do Sul com uma estabilidade mais ampla no hemisfério, com o papel de liderança desempenhado pelo Brasil (Roett, 2010). São exemplos como esses que nos demonstra as iniciativas brasileiras em elaborar e construir alianças estratégicas para sua maior projeção externa.

O protagonismo externo brasileiro, em certo sentido, apesar de abarcar dimensões político-econômicas, tem implicações diretas nas políticas sociais, pois todas elas estão relacionadas a um projeto nacional de desenvolvimento socioeconômico. Ou seja, essas parcerias estão sendo construídas na perspectiva de desenvolver o país - tanto social como economicamente. A lógica reproduz uma confluência de iniciativas que canalizam, ao final, para o desenvolvimento nacional e para a inserção externa do país. Todas elas estão relacionadas à postura global-multilateral que a diplomacia brasileira adotou a partir o início dos anos 2000 (Pecequilo, 2008). A política exterior de Lula combinou eixos tradicionais de política internacional com elementos inéditos de diversificação de parcerias e ativismo internacional. A diplomacia do governo Lula da Silva, segundo Oliveira (2005), passou a considerar o multilateralismo como um movimento amplo de desconcentração de poder no sistema internacional e fora baseado nessa premissa, principalmente, que nossa atuação externa se pautou para engajar-se em novas alianças e coalizões mul- 
tilaterais para permitir, ou mesmo garantir, uma inserção externa mais assertiva de nossa diplomacia. Nas palavras do próprio autor:

A diplomacia do governo Lula vem recuperando, pelo menos em parte, as tradições da agenda da Política Externa Independente e, ainda que com modificações significativas, a do Pragmatismo Responsável e Ecumênico do governo Geisel. (...) Portanto, a origem do protagonismo internacional brasileiro na atualidade parece ter sua inspiração nessa tradição da política externa brasileira, caracterizada como nacional-desenvolvimentista. Seus desdobramentos práticos estão consubstanciados na formação do Ibas - Fórum de Diálogo Índia, Brasil e África do Sul; na criação do G-20 - Grupo de países em desenvolvimento criado na fase final de preparação da V Conferência Ministerial da OMC; na aproximação com países africanos e árabes; na participação no G-4 - grupo composto por Alemanha, Brasil, Índia e Japão - em busca da reforma no Conselho de Segurança da ONU e das suas respectivas admissões nele como membros permanentes; na revalorização da inserção regional, inclusive ao se dispor a arcar com os custos do exercício da sua liderança, especificamente, no Mercosul - Mercado Comum do Sul - e na América do Sul, além de incentivar seus parceiros em desenvolvimento a também incorporarem a dinâmica regional às suas respectivas política externa, visando consolidar seus papéis de relevância regional. A missão de paz da ONU conduzida pelo Brasil no Haiti é ilustrativa dessa agenda política. (Oliveira, 2005, p. 3).

Ainda que esse processo de multipolarização esteja em andamento, o passo dado pelo governo nesse sentido fora importante para a inserção internacional de nosso país. Como apontou Vizentini (2005), a política externa no governo Lula fora o campo mais bem sucedido da política governamental. 


\section{OS ORGANISMOS INTERNACIONAIS}

Muito importante para a reputação internacional da conduta político-econômica de uma nação é sua avaliação diante de Organismos Internacionais. Instituições de alcance global como o FMI ${ }^{8}$, Banco Mundial ${ }^{9}$, a $\mathrm{ONU}^{10}$ e suas ramificações específicas e outras agências globais são exemplos de organizações de caráter multilateral que refletem a intenção de países em criar um mínimo de regulação em suas relações externas, sejam elas de qualquer natureza.

Do ponto de vista da avaliação internacional, nossa argumentação se baseará, principalmente, em papers desenvolvidos tanto pela CEPAL quanto pelo Banco Mundial. São importantes esses papers porque eles trazem à tona a percepção internacional acerca das políticas sociais aplicadas em território nacional, e com isso nos permite ter conhecimento de como a imagem do Brasil é veiculada no exterior e de que forma outros governos nos avaliam. Assim, a imagem externa do Brasil, contribuindo para uma maior inserção externa de nossos interesses, precisa ser trabalhada no sentido de aprovação por parte dos outros países, para, com isso, articular melhor nossa projeção externa.

No referido documento, aponta o Banco Mundial acerca do programa Bolsa Família:

As the largest conditional cash transfer in the developing world, the BFP has attracted significant attention both in Brazil and beyond. To date, the BFP has achieved some important efficiency gains and is showing exceptional targeting results, with $73 \%$ of transfers going to the poorest quintile and $94 \%$ going to the poorest two quintiles. Furthermore, studies have shown that the BFP played a significant role in the recent reduction in income inequality, which in turn has been instrumental in reducing extreme poverty. Indeed, results of the annual household survey (PNAD 2004) show that the

\footnotetext{
8 Para maiores informações: www.imf.org

9 Para maiores informações: www.worldbank.org

${ }^{10}$ Para maiores informações: www.un.org 
BFP accounted for a significant share (20-25\%) of Brazil's recent (and impressive) reduction of inequality and 16\% of the recent fall in extreme poverty. (Banco Mundial, 2007, p. 6).

O organismo internacional vê com bons olhos o programa nacional de transferência de renda, e aponta dados estatísticos fornecidos por órgãos nacionais, como a PNAD, como ferramentas importantes que contribuem para o embasamento das análises. A imagem do país, nesse sentido, é fortalecida diante das organizações. Assim, nossas políticas sociais, acobertadas pelas positivas avaliações internacionais, podem servir de exemplo para outros países que sigam o mesmo caminho que o nosso de combate à pobreza. E isso pode eventualmente nos auxiliar em nossa inserção internacional.

$\mathrm{O}$ documento ainda aponta para um possível cenário para $\mathrm{o}$ Brasil a partir de 2007, indicando alguns desafios a serem enfrentados e apostando na capacidade brasileira de continuar na tarefa de enfrentamento da pobreza. Ele aponta para duas principais agendas a serem seguidas pelo Brasil no futuro: a primeira consiste nos esforços em continuar aperfeiçoando a arquitetura básica do programa; a outra é centrada na inovação e nas reformas para promover a o desenvolvimento da agenda de combate à pobreza (Banco Mundial, 2007).

Outro trabalho realizado no sentido de avaliação das políticas públicas brasileiras foi disponibilizado pela CEPAL, em 2009, 2010 e 2011, que avaliam, entre outras coisas, o panorama social e econômico da América Latina e apontam dados e estatísticas que comprovam suas teses.

Os estudos, em geral, afirmam que houve diminuição da pobreza na região latino-americana no período recente e o crescimento econômico deu sinais de leve ascensão. Segundo os documentos, o Brasil, juntamente com o Panamá, Paraguai e Peru apresentaram diminuições de sua taxa de pobreza entre 0,9 e 2,2 pontos percentuais. Países como a República Dominicana e o Uruguai (setor urbano), diminuíram sua taxa pobreza em média de 3\% (CEPAL, 2010). Para os analistas cepalinos, ao considerar o período entre 2002 e 2009, a redução da pobreza tem sido possível graças a uma complementari- 
dade entre os efeitos de crescimento econômico e distribuição das rendas geradas a partir desse processo. De acordo com o documento de 2009, afirma os autores da CEPAL:

As mudanças distributivas ocorridas no período contribuíram parcialmente para a redução da pobreza, ainda que não em todo seu potencial. A variação das taxas de pobreza e indigência pode ser desagregada em dois componentes: o crescimento da renda média das pessoas, ou "efeito crescimento", e as mudanças na distribuição desta renda, ou "efeito distribuição". Este tipo de análise mostra que a queda da pobreza entre 1990 e 2008 teve no efeito crescimento seu principal fator explicativo, representando cerca de $85 \%$ da mesma, enquanto o efeito distribuição explica os $15 \%$ restantes. A contribuição das melhorias distributivas para a redução da pobreza ocorreu especialmente no período 2002-2008, durante o qual representou inclusive o papel principal na redução da pobreza em três países. A renda do trabalho é a fonte que contribuiu em maior medida para a redução a pobreza entre 1990 e 2008. (CEPAL, 2009, p. 12).

O reconhecimento nacional e internacional da importância que o gasto social público representa para a população mais pobre e a relevância do desenvolvimento social para potencializar o desenvolvimento econômico nacional têm levado os países da região a aumentar progressivamente os gastos neste setor da sociedade.

Segundo outro estudo, realizado em 2010, "a participação do gasto social no PIB passou de 12,2\% no período 1990-1991, para 18,4\% em 2007-2008. Em consequência, também aumentou consideravelmente a sua participação no orçamento, de pouco menos de $45 \%$ a cerca de $65 \%$ do gasto público total." (CEPAL, 2010, p. 33). No âmbito social e produtivo, seguindo essa linha de raciocínio, é relevante o aumento dos recursos destinados à construção de moradia, ao tratamento da água e do esgoto, ao fomento de pequenas e médias empresas, ao setor agroexportador, ao fortalecimento de políticas trabalhistas, e aos programas sociais, mormente os de transferência direta de renda - como o Bolsa Família - que "atualmente recebem 
recursos equivalentes a $0,4 \%$ do PIB regional e cobrem cerca de $20 \%$ da população latino-americana e caribenha (CEPAL, 2010).

A CEPAL, neste paper, ainda que tenha tratado do tema social da região latino-americana em geral, perpassa sua análise sobre a situação do Brasil e dos resultados alcançados pelo programa Bolsa Família, que foram citados acima. Essas estatísticas são importantes para defendermos nosso ponto de vista de que a imagem do Brasil frente às organizações internacionais, durante o período Lula da Silva, fora positiva e determinante para a inserção internacional de nosso país.

De resto, devemos esclarecer que o debate acerca da problemática social e da tentativa de ingerência externa através da ajuda econômica não está esgotado e necessita ser aprofundado. Nossa análise, embora se embase nos documentos oficiais de organismos nacionais e internacionais, somente fora realizada para demonstrarmos a avaliação internacional do Brasil frente às suas políticas sociais, e com isso apontar qual a imagem que o governo Lula da Silva transpôs durante sua gestão. Por isso, nossa argumentação caminha no sentido de defender esses documentos na medida em que eles complementam nossa análise, a qual, como já apontamos, avalia o impacto dos programas sociais do governo Lula da Silva como positivo para a inserção internacional do Brasil, mormente em sua política exterior de ampliação do horizonte diplomático e em sua projeção externa multilateral.

\section{CONCLUSÃO}

O período analisado, essencialmente entre 2002 e 2010 , durante os dois mandatos do governo Luiz Inácio Lula da Silva, foi escolhido devidamente pelo fato da ênfase atribuída por esse governo às políticas sociais no campo nacional, ao mesmo tempo em que empregava uma política externa voltada para o campo social. A escolha não fora feita de forma aleatória. O governo Lula da Silva, embora possa ser criticado sob diversos pontos de vista e sob qualquer outra natureza de suas políticas públicas, implantou uma política exterior ativa e cooperativa no campo das relações internacionais. Evidente que não devemos defender acriticamente as decisões tomadas por 
esse governo em matéria de relações exteriores, entretanto os acertos feitos na diversificação de parcerias, na defesa da autonomia brasileira frente às grandes potências, na busca soberana de participar progressivamente dos principais Fóruns Multilaterais, a iniciativa na criação do G-20 comercial, entre outros não podem deixar de serem destacados aqui. Os fracassos, que também são tantos outros, devem ser ressaltados e discutidos.

Em um período de tempo relativamente curto, o Brasil tornou-se um global player cada vez mais importante no cenário internacional, destacando-se nas áreas de energia, comércio e finanças. Empregou um conjunto de iniciativas organizacionais regionais que são jovens ainda, mas espera-se que amadureçam nos próximos anos, como apresentamos anteriormente. Com esses desenvolvimentos vem a responsabilidade de agir positiva e pragmaticamente em questões mais amplas, de importância global. A crescente influência econômica e comercial precisa ser combinada com uma política externa madura e responsável. Essa combinação servirá bem ao Brasil no momento em que sua trajetória ganha crescente atenção e respeito.

Assim, como tentamos demonstrar ao longo do trabalho, as escolhas em política externa feitas pelo presidente Lula foram decididas a partir de um viés social. A participação do Brasil no G-20, a busca por parcerias de natureza Sul-Sul, a diversificação das relações comerciais são iniciativas que carregam consigo o fardo histórico da dívida social que o Brasil empurra ao longo de sua história. Os frutos oriundos dessas iniciativas, se concretizados da maneira como os interpretamos inicialmente, trará benefícios diretos para a sociedade brasileira, refletindo num maior desenvolvimento econômico nacional e na redução gradativa dos índices de pobreza e miséria que afetam nossa sociedade. É nesse link entre política social e engajamento externo que tentamos demonstrar como é possível avaliar o impacto que os programas sociais nacionais tiveram sob a atuação externa brasileira, apontando para seus sucessos e demonstrando a aplicabilidade desse tipo de análise quando se compara duas políticas essencialmente distintas entre si. 


\section{REFERÊNCIAS}

ANANIAS, Patrus. As políticas sociais no encontro do Estado com a Nação. Revista Interesse Nacional, online, 9 de outubro de 2009.

ALMEIDA, Paulo Roberto de. Uma política externa engajada: a diplomacia do governo Lula. Revista Brasileira de Política Internacional, Brasília, DF, Vol. 47, nº. 1, p. 162-184, jan./jun. 2004.

ALTEMANI DE OLIVEIRA, Henrique; LESSA, Antônio Carlos (Orgs.). Relações Internacionais do Brasil: temas e agendas. São Paulo: Saraiva, 2006

ARAÚJO, José Prata. Um retrato do Brasil: balanço do governo Lula. São Paulo: Fundação Perseu Abramo, 2006.

. Guia dos Direitos Sociais: a igualdade social e as diferenças entre a esquerda e os neoliberais. São Paulo: Fundação Perseu Abramo, 2009.

BANCO MUNDIAL. Social Policy, Perceptions and the Press: an analyses of the media's treatment of conditional cash transfers in Brazil. Papel para discussão. Dez. 2010.

BARBOSA, Nelson; SOUZA, José Antônio Pereira de. A inflexão do governo Lula: política econômica, crescimento e distribuição de renda. In: GARCIA, Marco Aurélio; SADER, Emir (Org.). Brasil, entre o passado e o futuro. São Paulo: Fundação Perseu Abramo: Boitempo Editorial, 2010.

BRASIL. Ministério da Fazenda. Relatório Economia Brasileira em Perspectiva. Brasília, DF, 2010.

. Ministério das Relações Exteriores. Balanço da Política Externa Brasileira 2003-2010. Brasília, DF, 2010.

. Ministério do Desenvolvimento Econômico e Social. Balanço do Desenvolvimento Econômico Social. Brasília, DF, 2010.

CEPAL. Documento informativo. "Panorama social da América Latina". Santiago do Chile, 2009. 
. Documento informativo. "Panorama social da América Latina". Santiago do Chile, 2010.

. Documento Informativo. "Panorama da inserção internacional da América Latina e Caribe”. Santiago do Chile, 2010-2011.

DRAIBE, Sônia. Programas de Transferências Condicionadas de Renda. In: CARDOSO, Fernando Henrique; FOXLEY, Alejandro (Org.). América Latina: desafios da democracia e do desenvolvimento: políticas sociais para além da crise. Rio de Janeiro: Campus, 2009. p. 103-143

DULCI, Otávio. Transferência de renda e política social: modelos e trajetórias institucionais na América Latina. In: ENCONTRO DA ANPOCS, 33., 26-30 out. 2009, Caxambu. Anais eletrônicos. Campinas: Unicamp, 2009. p. 1-14.

GUIMARÃES, Samuel Pinheiro. Inserção internacional do Brasil. Revista Economia e Sociedade, Campinas, Vol. 17, p. 1-31, dez. 2001.

IPEA. Diálogos para o desenvolvimento: a experiência de desenvolvimento econômico e social sob o governo Lula. Vol. 2. Brasília, DF, 2010a.

. Perspectivas da política social do Brasil. Livro 8. Brasília, DF, $2010 \mathrm{~b}$. . Carta de Conjuntura. Rio de Janeiro, nº. 9, mar. 2010c.

MARQUES, Rosa Maria; MENDES Áquila. Servindo a dois Senhores: As políticas sociais no governo Lula. Revista Katálysis, Florianópolis, Vol. 10, no. 1, p. 15-23, 2007.

MATTEI, Lauro. Notas sobre programas de transferência de renda na América Latina. Textos para discussão, Florianópolis, nº. 10/20010, 2008.

OLIVEIRA, Marcelo Fernandes de. Alianças e coalizões internacionais do governo Lula: o Ibas e o G-20. Revista Brasileira de Política Internacional, Brasília, DF, Vol. 8, nº. 2, p. 55-69, 2005.

PECEQUILO, Cristina Soreanu. A política externa do Brasil no século XXI: os eixos combinados de cooperação horizontal e vertical. Revista Brasileira de Política Internacional, Brasília, DF, Vol. 51, n. 2, p. 136-153, 2008. 
POCHMANN, Márcio. O Estado e seus desafios na construção do desenvolvimento brasileiro. Carta Maior, São Paulo, 7 de dez. 2010.

ROETT, Riordan. O Brasil desponta como um player global. Revista Interesse nacional, online, $1^{\circ}$ de janeiro de 2010.

SADER, Emir. A vingança da história. 2. ed. São Paulo: Boitempo, 2007.

SARAIVA, Miriam Gomes. As estratégias de cooperação Sul-Sul nos marcos da política externa brasileira de 1993 a 2007. Revisa Brasileira de Política Internacional, Brasília, DF, Vol. 50, nº 2, p. 42-59, 2007.

SILVA, André Luís Reis da. As transformações matriciais da Política Externa Brasileira recente (2000-2010). Meridiano 47. Vol. 11, n. ${ }^{\text {1 } 120, ~ p . ~ 18-24, ~} 2010$.

VIGEVANI, Tullo; CEPALUNI, Gabriel. A política externa de Lula da Silva: a estratégia da autonomia pela diversificação. Contexto Internacional, Rio de Janeiro, v. 29, n. 2, p. 273-335, 2007.

VIZENTINI, Paulo Fagundes. De FHC a Lula: uma década de Política Externa (1995-2005). Civitas: Revista de Ciências Sociais, Porto Alegre, Vol. 5, no.2, p.381-397, jul./dez. 2005.

WEISSHEIMER, Marco Aurélio. Bolsa Família: avanços, limites e possibilidades do programa que está transformando a vida de milhões de famílias no Brasil. São Paulo: Fundação Perseu Abramo, 2006.

Recebido: 20/11/2012

Aprovado: 19/12/2012 